\title{
A Multivariable, Two-Dimensional Plot of Electromagnetic, Electric Field and Seismic Information for the Characterization of Earthquake Precursors
}

\author{
John Ricken Wright \\ Emeritus Professor of Chemistry, Southeastern Oklahoma State University, Durant, Oklahoma, USA \\ Email: cotterobservatory403@gmail.com
}

How to cite this paper: Wright, J.R. (2020) A Multivariable, Two-Dimensional Plot of Electromagnetic, Electric Field and Seismic Information for the Characterization of Earthquake Precursors. Open Journal of $\mathrm{Ge}$ ology, 10, 213-234.

https://doi.org/10.4236/ojg.2020.103012

Received: February 13, 2020

Accepted: March 14, 2020

Published: March 17, 2020

Copyright $\odot 2020$ by author(s) and Scientific Research Publishing Inc. This work is licensed under the Creative Commons Attribution International License (CC BY 4.0).

http://creativecommons.org/licenses/by/4.0/

\begin{abstract}
Removal of the electrical shielding from a type of Fourier transform seismometer overlays seismic information with Extremely Low Frequency-range (ELF) electromagnetic signals between about $0.3 \mathrm{~Hz}$ and $36 \mathrm{~Hz}$ (the ITU-designated range of ELF is 3 to $30 \mathrm{~Hz}$ ). The observed signals originate in the electric power grid, shown clearly by the fact that they are sum and difference heterodyne products with the power grid's higher harmonics of 60 $\mathrm{Hz}$, typically the 36th and 37th, because the seismometer's chosen frequency modulation (FM) carrier frequency is roughly $2200 \mathrm{~Hz}$. It is especially interesting that on 2017-03-19, prior to 14:25:12 UTC, the instrument recorded an 11 minute sequence of $20.3 \mathrm{~Hz}$ ELF outbursts that culminated intimately with a 3.2 magnitude earthquake located a few miles west of Bardwell KY. These $\sim 20.3 \mathrm{~Hz}$ ELF signals, very near the third Schumann resonance frequency, have been recorded numerous times. They are distinctive and fairly strong, ranging 15 to $30 \mathrm{db}$ or more above the noise floor, but definitely not an every-day event; months can pass without them. So far most of these ELF signals do not have an intimately associated earthquake, with the event of 2017-03-19 being one of only two exceptions recorded thus far. That quake's location was more than one hundred miles from the instrument, in the New Madrid Seismic Zone (NMSZ). The second case, a quake in Kansas, was about three times farther from the instrument, and its ELF signals were correspondingly weaker. Those other, unassociated electromagnetic events might come from quakes too weak to detect, but it should be noted that stronger, easily detected quakes also rarely exhibit any ELF/seismic "connectivity". This paper describes an instrument that overlays ELF, electric field and seismic signals. The instrument's two-dimensional (2D) output has a time axis (hori-
\end{abstract}


zontal) resolution of $\sim 3$ seconds and an ELF frequency (vertical) resolution of $\sim 0.3 \mathrm{~Hz}$.

\section{Keywords}

Seismoelectromagnetics, Premonitory, Connectivity, 20 Hz ELF, Power

Grid as Antenna, FM Seismometer, Multivariable Display, Electric Field, Rosetta Stone

\section{Introduction}

In February of 2011, a magnitude 4.7 Arkansas earthquake shook Cotter Arkansas, where the author of this paper lives. That experience motivated a retirement preoccupation: the construction of a sensitive seismometer, followed by observations and experiments with it. The completed seismometer was given some thermal insulation and affixed to concrete in the basement, and being eager to see a signal, some unused, already installed bell and phone wires were linked together to get a one-wire signal path between the seismometer and a Dell laptop in the den room at the far end of the house. Thanks to the electric field sensitivity of CMOS and similar devices in the signal path and a seismic stimulus of four deep knee bends near the seismometer, a strong signal came through. The seismometer thus worked properly on its first try.

The author very nearly installed a coaxially-shielded signal cable at that point, but the SPECTRAN II Fourier transform operating system was already up and running and in capture mode, i.e. saving data frames. Out of curiosity, the system was allowed to continue that way, which led to the interesting findings reported here, and as of February, 2020 the roll of RG-6U shielded cable is still laying, unused, on a table in the den room.

Among the very first seismic events recorded were the large Indonesian quakes of April 11, 2012. Their largest P-, S- and R-waves went completely off-scale. Seismometer sensitivity is comparable to the local network instruments. The North Korean thermonuclear test also recorded nicely at the adopted normal scan rate, and the instrument detects microseisms if the scan rate is modified for their lower frequencies.

It was noticed almost immediately that recorded signals at 2160 and $2220 \mathrm{~Hz}$, nearly as prominent as the seismic baseline (at about $2200 \mathrm{~Hz}$ ), were divisable by 60 , and thus were harmonics of the power grid frequency (e.g., $2160 \mathrm{~Hz} / 60=$ 36). The unshielded one-wire signal path between the seismometer and the computer was picking them up from the house electrical wiring and/or street wiring. Furthermore, and much more significantly, it was noted that the $60 \mathrm{~Hz}$ harmonics were also carriers of ELF range signals, which showed as sum and difference frequencies symmetrically above and below the plotted 2160 and 2220 $\mathrm{Hz}$ harmonics. These were thought to be and later confirmed as mostly originating in HAARP experiments conducted at Gakona Alaska. There were at least 
two intentional HAARP shutdowns, and the noted signals disappeared immediately after those shutdowns. There was a lot of activity near $1 \mathrm{~Hz}$ near the end of military involvement, and a period of apparent low activity followed when the transmitting system at Gakona was passed to the University of Alaska. Then came a quake-related ELF event on March 19, 2017. An eleven minute sequence of $20.3 \mathrm{~Hz}$ outbursts ended in a 3.2 magnitude New Madrid Seismic Zone earthquake.

How could the power grid acquire these ELF signals? The power grid, as-is, amounts to a type of ELF radio receiver. Its hundreds of miles of interconnected wiring in the central region of the US is thus spatially large, a good antenna for receiving globally originated extremely low frequency signals. Also, the grid's partially power saturated transformers are non-linear devices, able to create excessive harmonics of the fundamental frequency if not at least partially corrected for non-linearity of its loads; thus, the possibility for heteodyne mixing of the 60 $\mathrm{Hz}$ harmonics with incoming ELF signals is worth considering [1]. This viewpoint is offered as a reasonable explanation for the observed man-made HAARP signals as well as the occasional, apparently natural signals near Schumann resonant frequencies, both of which are evidently picked up by the power grid, but the concept needs quantitative verification, perhaps using numerical electromagnetic code or similar computations [2].

A second kind of electrical phenomenon happened during overhead thunderstorms. Ordinary (-) lightning strikes, where electrons move downward, caused a discontinuous downward deflection of the seismic baseline, meaning that the circuit behaved like a moderately sensitive electrometer. The instrument also detected the rare (+) lightning discharges, where the seismic baseline deflected upwards. The detection range of lightning electrometric effects was only about 15 miles based on flash to thunder times. This phenomenon apparently isn't a power grid effect, but rather, is due to the single wire signal link floating between field effect electronic components of the seismometer and also in the computer's sound card.

The following is a description of a multivariable instrument that uses fast Fourier transform methodology to create 2D recording frames of time versus frequency that contain 1) an image of the seismic amplitude and frequency overlaid with 2) a bipolar, ELF range emission spectrum. Sudden electric field effects 3) are also detected as vertical discontinuities of the seismic baseline. The described output format thus has merit for detecting possible ELF electromagnetic precursors of earthquakes, and examples of actual recordings containing probable ELF precursors and possible quake-related electric field changes are presented and discussed here. All of the stated signals include an amplitude variable.

\section{The Multivariable Seismometer and Its Experimental Details}

1) The seismometer part of the instrument and its theory of operation 
The multivariable instrument described here is based on a Lehman-type seismometer with a mass balance resonant frequency of $1.0 \mathrm{~Hz}$. Seismic signals are detected photometrically using a light beam and knife edge sensor (but almost any seismometer with appropriate gain settings should work as well, or better). The knife, a thin razor, is attached to the mass balance (thus moves vertically), and its edge is located very close to a $0.5 \mathrm{~mm}$ diameter LED. The latter is an ordinary white LED, and its plastic lens has been cut flat, very close to the light emitting element, ground and polished. The photometer's sensor, a CdS photoconductor, is located about $50 \mathrm{~mm}$ beyond the knife edge. The seismometer is entirely $12 \mathrm{~V}$ battery powered, thus has no direct Earth-ground.

For a comparison of the FM seismic instrument with FM radio communications (the main application of FM modulation), in the latter the transmitter's carrier amplitude is kept constant while the carrier's frequency varies in step with a modulating signal. The FM seismic instrument processes the signal from the seismometer the same way. However, FM communications receivers usually have one or more signal amplification stages and a limiter. The reason for the limiter is to restrict bandwidth so that only the strongest modulation lines reach the FM demodulator, thus reducing random noise and also keeping the output signal level constant. FM reception is good over fairly large geographical areas but becomes notoriously unreliable when the signal bandwidth drops below the limit level, i.e., when the received signal itself is suddenly becoming weak. Something similar happens to an FM seismometer at the weak signal limit.

In contrast, the FM seismometer doesn't use a limiter because seismic amplitude is proportional to the number of modulation lines in the sidebands; the sidebands are not restricted and Fourier transformation causes them to plot bipolar, vertically along the frequency axis of the instrument's 2D recordings, where time is horizontal and frequency vertical. This measure is necessary to avoid distorting signal amplitude. Weak signals begin at about $0.5 \mathrm{~Hz}$, and a strong signal at $72 \mathrm{~Hz}$, peak-to-peak, is beginning to go off-scale. For another comparison, a magnitude 2.5 earthquake in north central Oklahoma would cause roughly a $0.5 \mathrm{~Hz}$ weak signal deflection in north central Arkansas.

Experience has taught that the 2D recordings are best when the seismometer's plotting rate is adjusted for a Fourier transform resolution limit roughly one half of an instrument's resonant frequency or less, meaning with $\mathrm{f}_{\mathrm{r}} \sim 0.5 \mathrm{~Hz}$ and $\mathrm{f}_{\mathrm{m}}=$ $1.0, \mathrm{~Hz}$ respectively in the case of the prototype instrument. The resolution of plotted resonant frequency lines in a Lehmann FM seismometer is similar to diffraction disks at Dawes limit in optical instruments. Seismic signals are thus plotted with fill, and the FM method does an especially good job of revealing amplitude variations and outbursts during seismic events. Because of the modulation sidebands, the plotted seismic frequencies above $\sim 1.0 \mathrm{~Hz}$, i.e., of the $\mathrm{P}$ and S-waves, have bilateral symmetry with respect to the seismic baseline. Furthermore, the chosen FM modulator also tracks frequencies much lower than the transform's resolution limit, though without fill, because they amount to 
slow, periodic variations of the seismic baseline. R-wave signals thus also plot correctly. The 2D recordings are similar to conventional seismograms (Figure 1 and Figure 2).

2) How the seismometer behaves at its $1 \mathrm{~Hz}$ resonant frequency (theory continued).

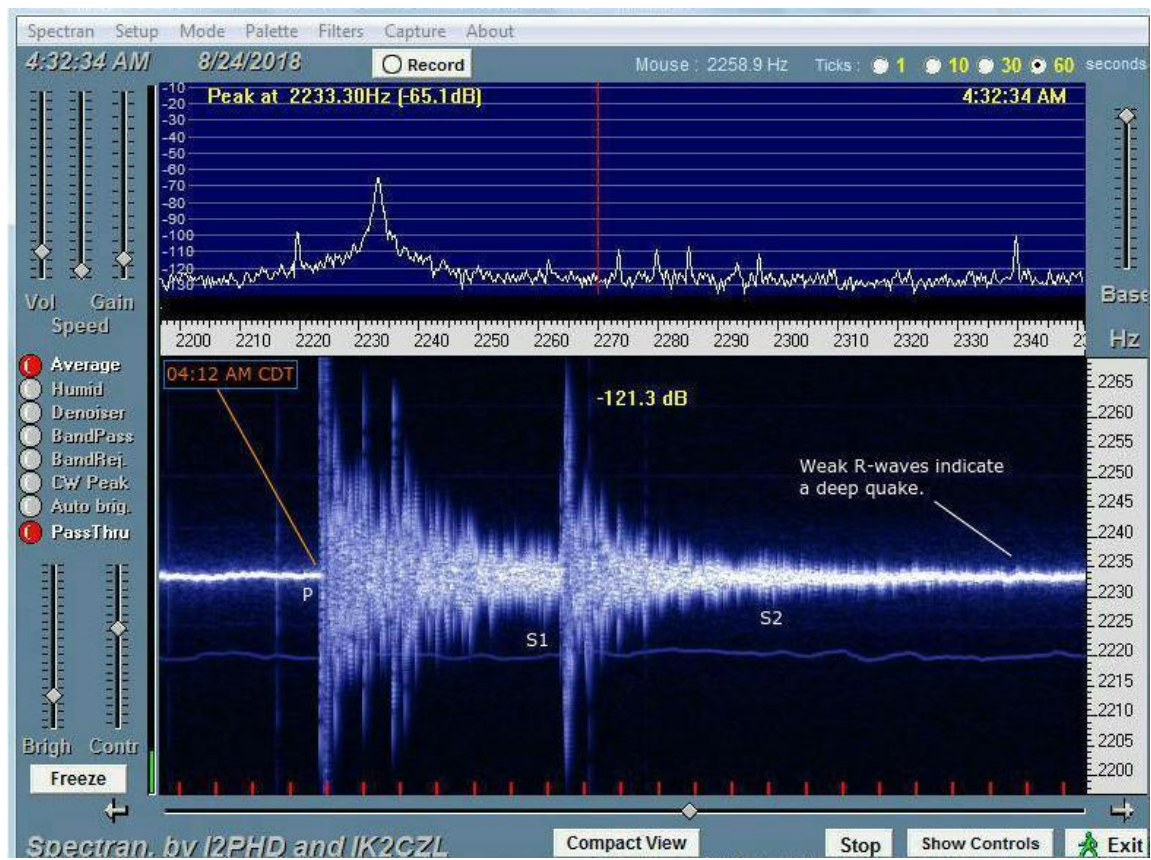

Figure 1. Peruvian Earthquake of 2018-08-24 09:12 UTC mag 7.1, recorded by the multivariable seismometer located at Cotter, Arkansas, which has an "unofficial" identitfier for record-keeping purposes, COTR2.

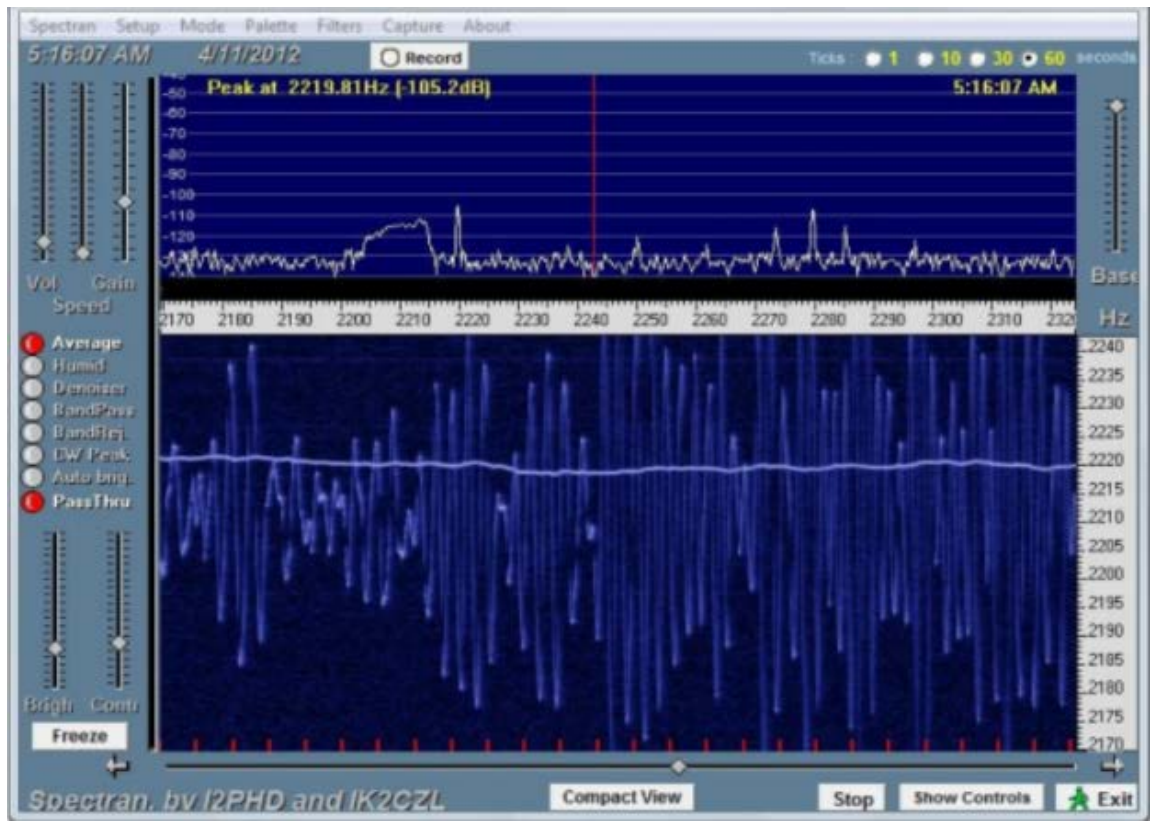

Figure 2. R-waves from the Indian Ocean earthquake, 2012-04-11, mag 8.6, also recorded by the multivariable seismometer, COTR2. 
E. H. Armstrong pioneered FM modulation [3], and FM modulation can be treated quantitatively using the mathematics of Bessel functions [4]:

Formulating in the time domain:

$$
v=a_{c} \sin \left(f_{c} t+M \sin f_{m} t\right)
$$

where $M$ is the modulation index and $f_{c}$ is the FM carrier frequency, about 2200 $\mathrm{Hz} ; f_{m}$ is the carrier modulation frequency, i.e., the mass balance resonant frequency of $1 \mathrm{~Hz}$ in this case.

Using Bessel functions, this expression can be rewritten to describe the modulation sidebands. The result is an infinite series, where $J$-values determine sideband line amplitudes:

$$
\begin{aligned}
v= & a_{c}\left\{J_{0}(\delta) \sin \left(f_{c}\right)+J_{1}(\delta)\left[\sin \left(f_{c}+f_{m}\right) t-\sin \left(f_{c}-f_{m}\right) t\right]\right. \\
& +J_{2}(\delta)\left[\sin \left(f_{c}+2 f_{m}\right) t+\sin \left(f_{c}-2 f_{m}\right) t\right] \\
& \left.+J_{3}(\delta)\left[\sin \left(f_{c}+3 f_{m}\right) t-\sin \left(f_{c}-3 f_{m}\right) t\right]+\cdots\right\}
\end{aligned}
$$

To cite two examples of line descriptions, the factor $\left(f_{c}-2 f_{m}\right)$ denotes a lower sideband line $2 \mathrm{~Hz}$ below the carrier, and $\left(f_{c}+f_{m}\right)$ is the $1 \mathrm{~Hz}$ upper sideband line, etc.. This series is infinite, but in the seismometry application, even where bandwidth limiting isn't allowed, a signal strong enough to create sidebands with only 100 lines each is already off-scale. This is because the coefficients of $f_{m}$ are integers in steps of one $\mathrm{Hz}$, and Fourier transformation stacks the lines close together, laterally, along the frequency axis of the 2D plot, which is effectively also a seismic amplitude coordinate of the recording, e.g.:

$$
f_{m}, 2 f_{m}, 3 f_{m}, \cdots, n f_{m}, \cdots, \text { etc. }
$$

If there is no seismic signal the above expression reduces to: $v=a_{c} J_{0}(\delta) \sin \left(f_{c} t\right)$, which is the baseline condition, e.g., a straight, theoretically featureless line along the time axis in a time versus frequency plot (but there will be some noise). The modulation spectrum, as seen on a spectrum analyzer will generally look like (Figure 3) shown here:

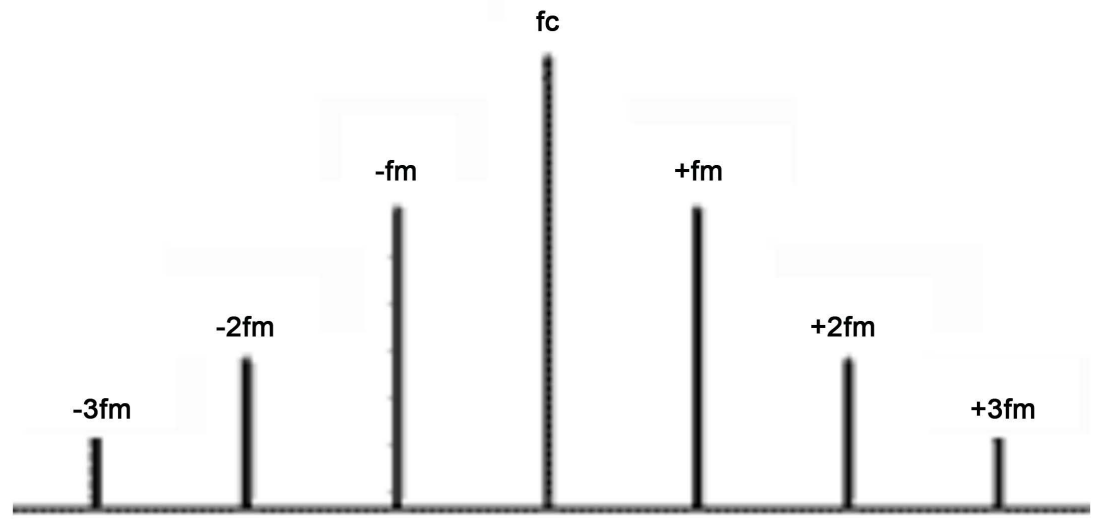

Figure 3. An FM modulation Spectrum. Frequency is horizontal and spectrum line and carrier magnitude is vertical. The modulation lines, fm, are spaced $1 \mathrm{~Hz}$ apart in upper and lower sidebands around a $2200 \mathrm{~Hz}$ carrier frequency, fc. 
The SPECTRAN II Fourier transform program used to create the seismometer's $2 \mathrm{D}$ recordings acts on the FM signal coming from the CD4046BE modulator, which has a modulation spectrum like (Figure 3), where frequency is horizontal and line magnitude is vertical. In the process of obtaining (Figure 4), SPECTRAN II rotates (Figure 3). 90 degrees clockwise, followed by flipping the frequency axis 180 degrees, i.e., end for end, around the magnitude axis. Finally, magnitude is then rotated 90 degrees upward, around the frequency axis, toward your eye, to become the Z-axis (plotted signal "brightness"). Thus, frequency ends up being along the vertical axis and time is horizontal in the resulting $2 \mathrm{D}$ display. Compare (Figure 4 and Figure 5), below.

\section{3) Other notable properties of the FM seismometer.}

FM seismometry cannot use the space saving stacked trace plot of USGS instruments because it is a $2 \mathrm{D}$ entity and the entire area is meaningful. Data are thus saved frame by frame as images. The instrument runs unattended continually, and the folder of time ordered data frames is reviewed for seismic and ELF events whenever it is convenient.

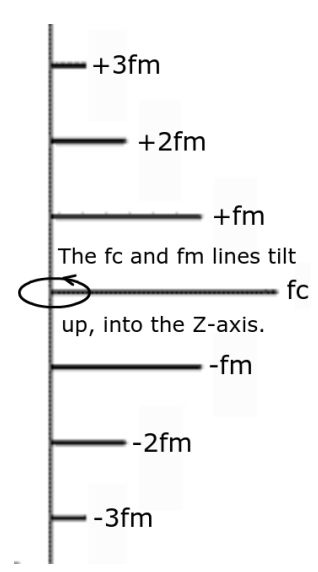

Figure 4. The Carrier and Modulation Lines Tilt up Toward the Eye, into the Z-axis.

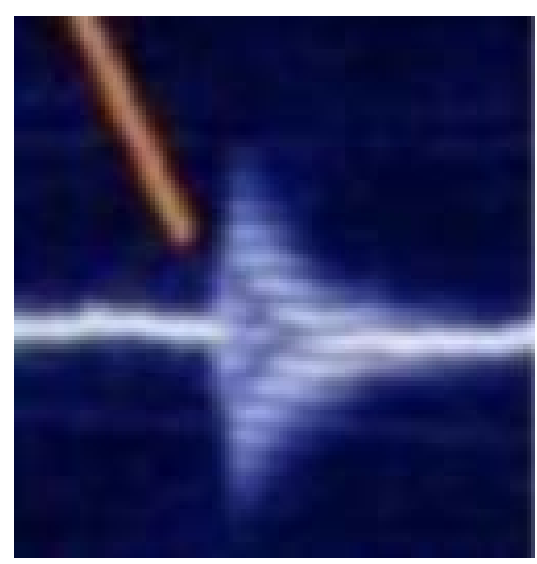

Figure 5. Four knee bends one second apart on the floor above the basement. The baseline, crossing horizontally, is the carrier frequency, fc, and at least 6 FM modulation lines, $\mathrm{fm}$, are discernable in both the upper and lower sidebands. Magnified image from a multivariable seismometer recording by COTR2. 


\section{4) The Seismometer's Electronic Circuit and Controls.}

The functional electronic parts of the instrument are shown in (Figure 6) and Table 1, below.

\section{5) Electromagnetic Signal Acquisition}

A single, unshielded signal wire, without a ground, runs from the output of the seismometer's voltage controlled oscillator, which is its FM modulator, to the microphone input of a Dell laptop's sound card. Time domain seismic and electric field signals generated in the Lehman seismometer and CD4046BE integrated circuit thus pass through the FM modulator and continue to the laptop as modified time domain signals.

There are other time domain signals present in that unshielded wire because the variables are, at least, ELF frequency and amplitude, electrometer signal polarity and amplitude, and seismic signal profile and amplitude. The wire itself

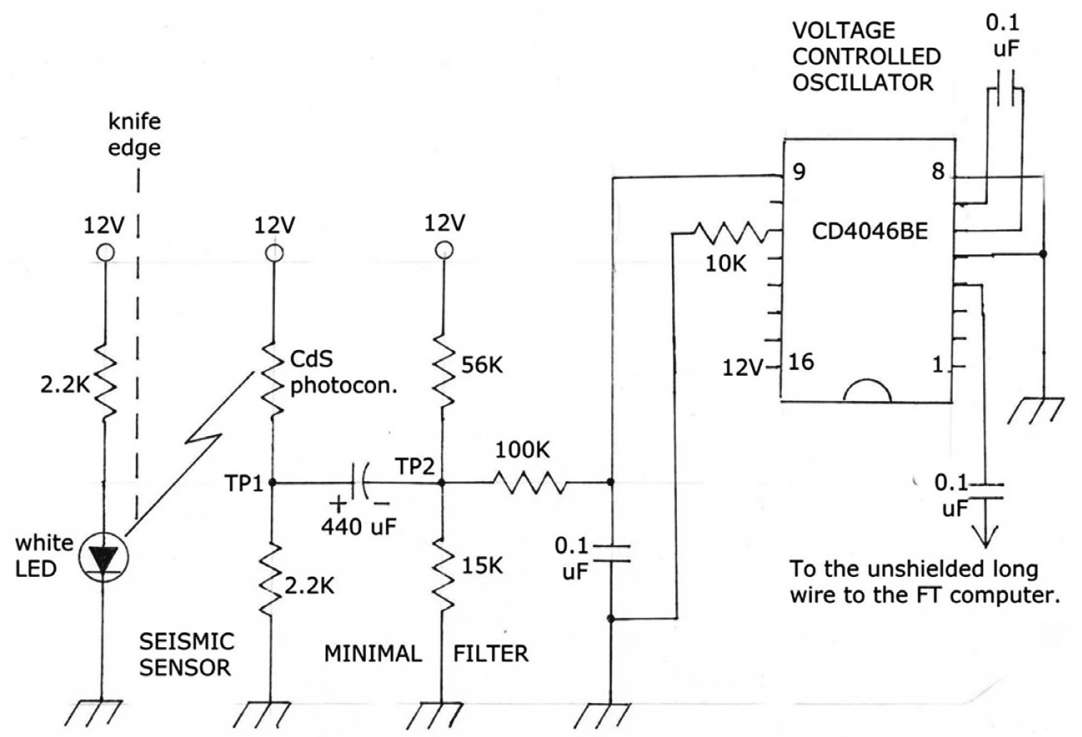

Figure 6. The instrument's seismic sensor, filter and FM modulator circuit diagram. Consider tuning the seismic baseline up and down by making either the 4046 capacitor between pins 6 and 7 or the resistor from pin 11 to ground, variable by about 20 percent. Sharpen the seismic baseline by making the white LED's $2.2 \mathrm{~K}$ load resistor capable of being increased to $5 \mathrm{~K}$, possibly more; it will depend on the instrument. When adjusting the knife edge for maximum instrument sensitivity, check the Voltage between TP1 and TP2 for correct polarity, and the Voltage from TP2 to local ground for about 3 Volts DC. SPECTRAN II controls the ELF baseline.

Table 1. Confirm or enter the appropriate values for the following SPECTRAN II parameters before trying to record seismic data.

\begin{tabular}{ccc}
\hline \multicolumn{3}{c}{ Recommended Initial Settings for the SPECTRAN II Program. } \\
\hline Frames Per Second 0.42 & Overlap 1.72 & Sampling Rate 8000 \\
Peak Frequency 2156.59 Hz & Times 2 Avg & Moving Avg \\
Horizontal scan & Freq offset 0 & USB \\
FFT size 32,768 & Resolution $0.24 \mathrm{~Hz}$ & IQUE, 0; 0QUE, 7
\end{tabular}


amounts to an antenna for picking up electromagnetic signals from the house and street wiring. Most notable in the $2 \mathrm{D}$ plot are the harmonics of $60 \mathrm{~Hz}$, like 2160 and $2220 \mathrm{~Hz}$; adjust one or the other of those to mid-way between the top and bottom of the 2D display. Increase SPECTRAN II gain, but don't significantly broaden the harmonic's linewidth. Then tune the seismic carrier frequency to about $5 \mathrm{~Hz}$ above or below the $60 \mathrm{~Hz}$ harmonic's frequency, and adjust the seismometer baseline for a sharp signal, usually by decreasing seismic gain relative to the harmonic.

The 36th and 37th harmonics alone were not especially interesting, but when new signals began showing up as sum and difference frequencies with respect to the 36th and 37th, things turned interesting. These certainly appear to be heteodyne products with the $60 \mathrm{~Hz}$ harmonics, and they are clearly in the ELF range of frequencies, or lower, e.g., as low as $0.5 \mathrm{~Hz}$. Others ranged upward to about 30 Hz. At least part of these electromagnetic emissions came from HAARP experiments. More recently, quake-associated ELF events at $20.3 \mathrm{~Hz}$, near the 3rd Schumann resonance mode, have been recorded by the multivariable instrument.

There is clear evidence that the heterodyne mixing of ELF signals with the power grid's $60 \mathrm{~Hz}$ harmonics takes place in the power grid itself, not somehow in or after the unshielded signal wire or in the sound card's electronics (see also electric field detection, below). All time domain signals, including the electric field effects noticed during thunderstorms and possibly during quakes and quake precursors, pass through that wire before Fourier transformation in the computer, yet the seismic carrier at about $2200 \mathrm{~Hz}$ shows no such heterodyne mixing with those same ELF signals. That is a reasonable outcome because a 150 $\mathrm{ft}$ wire is a puny ELF antenna, while the power grid has enormously more wiring.

The seismic and electric field signals both process through the FM modulator, and the long, unshielded signal wire picks up ELF-range signals coming from the local power wiring. That wire connects capacitively to pin 4 of the CD4046BE voltage-controlled oscillator, which has no earth ground (it is battery powered), and at the other end it goes to the microphone input of the computer's sound card, usually the second ring of the sound card's TRRS plug, which also has no earth ground path. Resist the temptation to connect a ground return conductor between the seismometer and computer ends of that wire!

\section{6) Electric field detection}

The author has done little to develop this feature of the instrument, but common sense says to keep it. It was found diagnostically that by temporarily placing a 10 megohm resistor between the FM modulator and the unshielded signal wire, the electrometer's lightning sensing function was stopped. Yet there was still a usable seismic baseline. The sensitivity to overhead thunderstorms is clearly due to the CD4046BE integrated circuit behaving as a moderately sensitive electrometer. See (Figure 7), below. 


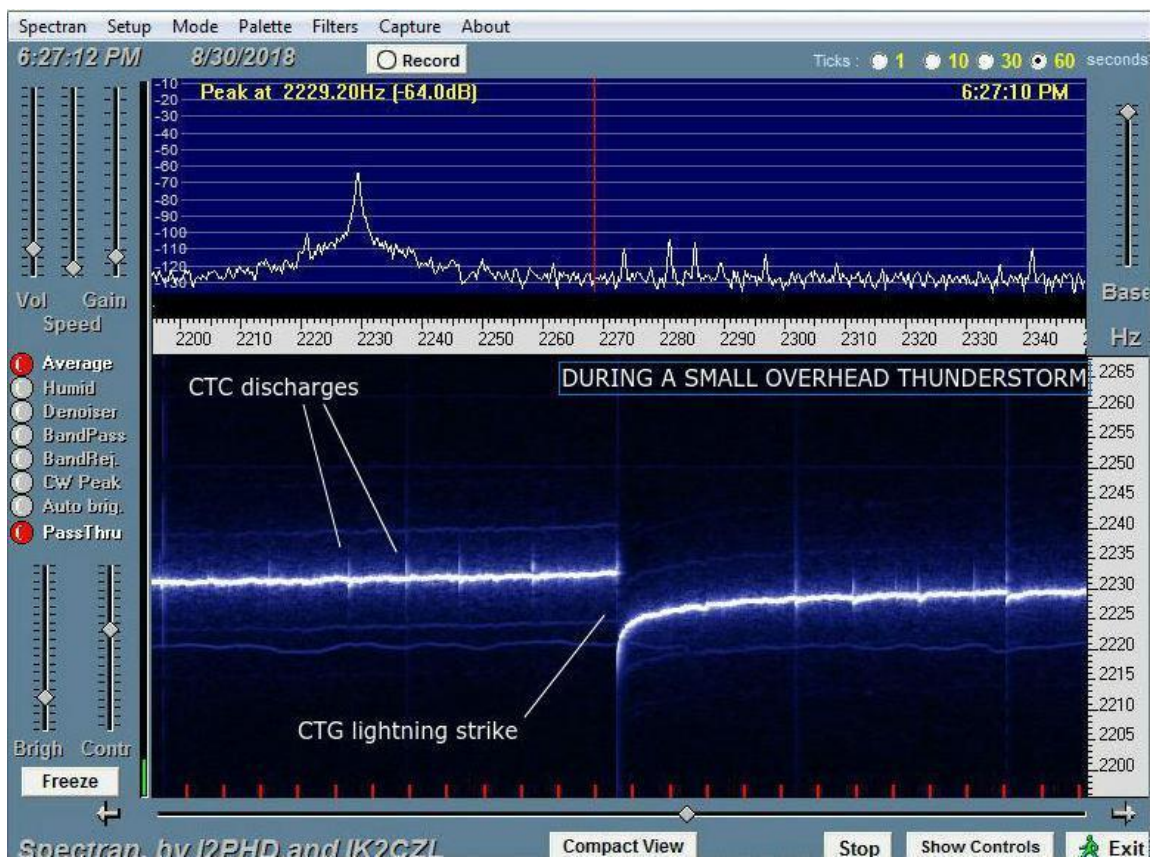

Figure 7. Electrometer mode of the instrument. Both cloud to cloud, CTC, and cloud to ground, CTG, electrical discharges are detected. Recorded by the multivariable instrument, COTR2. Thunderstorms and quakes rarely happen simultaneously.

\section{7) Fourier transform signal processing using SPECTRAN II}

Given a working, sensitive seismometer and a laptop computer with Windows 10 or Linux, SPECTRAN II is the component part that brings the multivariable seismic instrument together; it is free software, provided that it isn't used for financial gain [5]. SPECTRAN II uses the computer's sound card to digitize analog signals for the purpose of time-ordered Fourier transformation.

First, bring up the computer and enter or confirm Table 1's reasonable values for SPECTRAN II's operating parameters before using the instrument:

Click on the vertical row of buttons so that only the top button "average" and the bottom one "pass thru" are colored red; but, eventually, test all the controls, to learn what they do. The $0.24 \mathrm{~Hz}$ resolution limit (not $0.50 \mathrm{~Hz}$ ) is splitting hairs, but comes closer to the true $\mathrm{f}_{\mathrm{r}}$ value.

\section{Results and Discussion}

(Figure 8) illustrates one specific type of man-made, ELF-range signal that was recorded by the multivariable FM seismometer during the final military years of HAARP. There were other types of signals from HAARP and similar sources. The recording has no significant seismic activity along its indicated seismic baseline, but there is a minor positive electric field event along that baseline, to the right. Above the seismic baseline is another line that varies vertically by as much as $2 \mathrm{~Hz}$ but averages $2220 \mathrm{~Hz}$ in a random way; it is the 37th harmonic of the $60 \mathrm{~Hz}$ power grid frequency, which can be thought of as a kind of electromagnetic baseline, or signal carrier. Its variability is 37 times that of the actual $60 \mathrm{~Hz}$ 


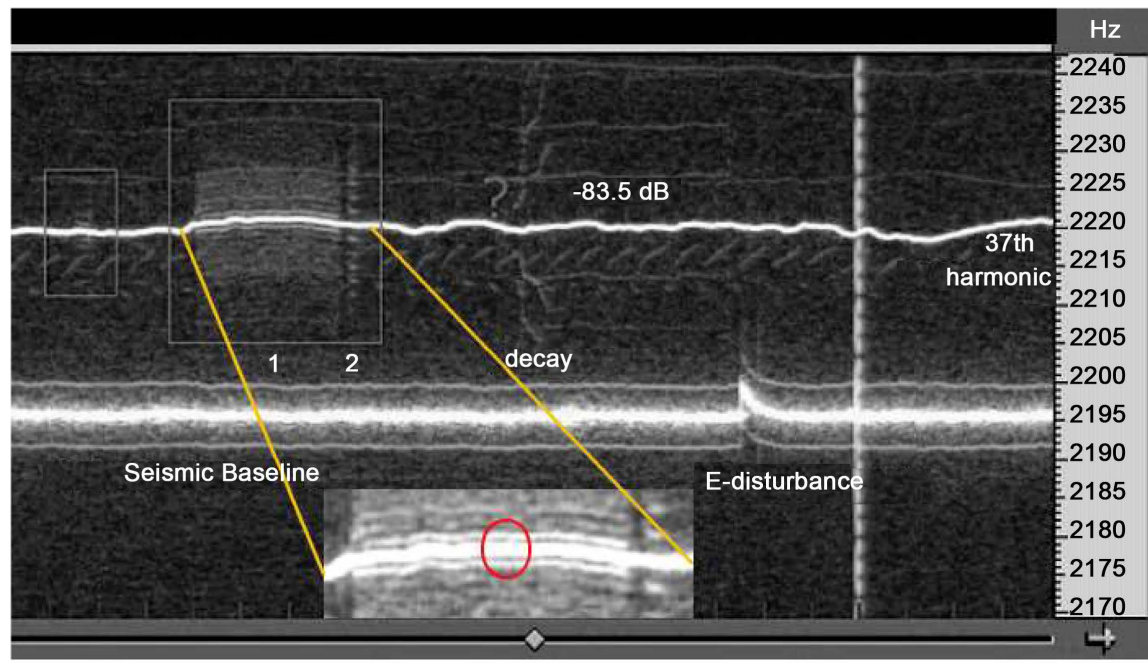

Figure 8. Probably signals from a HAARP experiment, one of many man-made signals recorded by the COTR2 multivariable seismometer.

system frequency and the wander originates in the mechanical nature of generators and their imperfect rotational frequency regulators. The variability is actually useful for identifying heterodyned ELF signals, especially those that are intermittent, and the instantaneous frequency difference in $\mathrm{Hz}$ between heterodyne pairs, symmetrically above and below their electromagnetic baseline, is the preferred way to measure their frequency (measure the difference between the sum and difference frequencies, i.e., the heteodyne pair, and divide by two).

The brighter middle line in the red-citcled part of the enlarged, contrast enhanced inset at the bottom of (Figure 8) is the 37th harmonic of $60 \mathrm{~Hz}$, near $2220 \mathrm{~Hz}$, and the lines immediately above and below the 37th are heterodyned sum and difference frequencies due to an incoming $1 \mathrm{~Hz}$ signal, almost certainly generated during a HAARP experiment. That signal is not FM modulated because signals from the power grid do not pass through the FM modulator.

This looks like some kind of induction/decay experiment, with induction being an ELF irradiation, i.e., a long period spaced from the $60 \mathrm{~Hz}$ harmonic by about $1 \mathrm{~Hz}$, then a brief period near $2 \mathrm{~Hz}$ almost immediately afterward. After a delay, following the question mark, comes a chirped emission of ELF, which decays. If the $1 \mathrm{~Hz}$ irradiating sidebands consisted of the inner two, alone, the irradiating source would be a $1 \mathrm{~Hz}$ sine wave, but there are numerous sideband components, indicating something like a $1 \mathrm{~Hz}$ rectangular wave irradiation. HAARP literature [6] notes that the latter happens when the shortwave heater beam is scanned back and forth across the electrojet to generate ELF radiation. The main points here are to show that the power grid picks up environmental electromagnetic radiation at least down to $\sim 1 \mathrm{~Hz}($ (); that $1 \mathrm{~Hz}$ modulation lines are completely resolved along the vertical frequency axis; and by analogy to optics the frequency resolution is actually near $0.24 \mathrm{~Hz}$ (half overlap of signal lines is analogous to the half-overlap of two Airy discs in an image at the resolving limit). 
On March 19, 2017, came a magnitude 3.2 earthquake west of Bardwell Kentucky (Figure 9), literally directly beneath the Mississippi River, and possibly also the location [7] of one of the major quakes of the New Madrid Seismic Zone's most recent active period, 1811 - 1812 (see a good map of that zone [7]). The modest March 19, 2017 quake was preceded by 11 minutes of ELF outbursts at $20.3 \mathrm{~Hz}$, and the final, larger outburst of ELF coincided with the actual beginning of the seismic event see (Figure 10), below.

The author perceives the above kind of recording as a type of electronic Rosetta Stone for revealing connectivities between seismic and electromagnetic events. For example, the arrival of the larger, final ELF outburst at Cotter from the quake's location was virtually instantaneous, but the obviously staggered arrival of the seismic wave, approximately 0.6 minute later, is consistent with the seismic wave travel time between Bardwell KY and Cotter AR. Note carefully that SPECTRAN II processes the seismic, electromagnetic and electric field signals together, in real time, so there is no meaningful relative time error between the recorded seismic, electromagnetic and electric field signals.

Mar 19, 2017

U40A HHZ RG 00

(Yellville, AR)

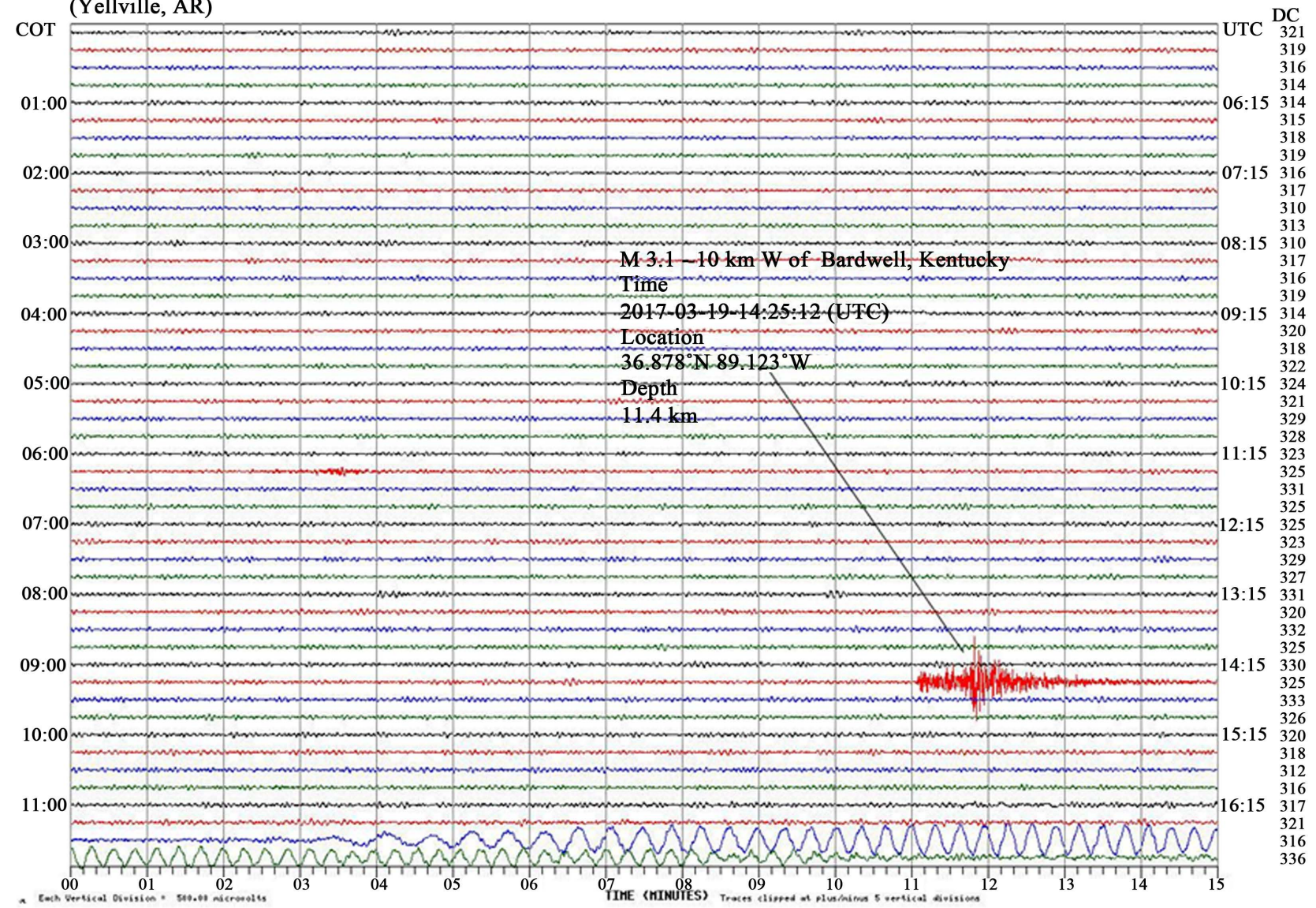

Figure 9. U40A recording of the 2017-03-19 seismoelectromagnetic earthquake. U40A is the seismic network instrument nearest to Cotter Arkansas. Courtesy of Center for Earthquake Research and Information (CERI), University of Memphis https://www.memphis.edu/ceri/seismic/heli.php. 


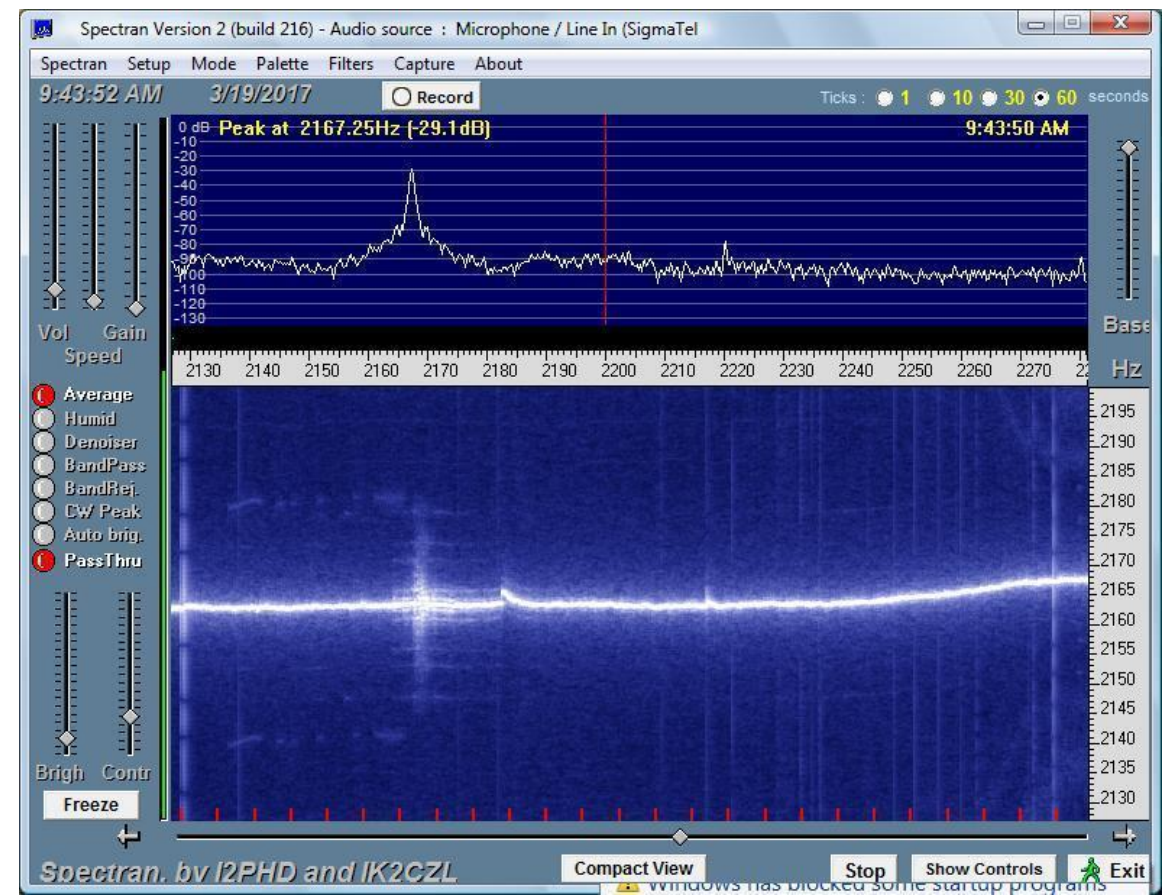

Figure 10. Seismic sensitive recording of the 2017-03-19 Kentucky/Mississippi River earthquake, recorded by the multivariable instrument, COTR2. This recording does not include the first four ELF outbursts because they are in the preceding data frame; the latter is (Figure S1) in the supplementary file.

At the time of the Bardwell Kentucky quake the author was sending the composite signal from the unshielded wire to two computers, one adjusted for a better seismic signal (Figure 10), above, and the other for a better electromagnetic signal (Figure 11), below. The latter computer recorded all of the ELF outbursts but almost missed the lower member of the $20.3 \mathrm{~Hz}$ heterodyned pair. (Figures 9-11) thus document how that event recorded, with 9 being from the Arkansas Geophysical Network's instrument, U40A, near Lead Hill Arkansas, an ordinary seismometer, 10 from the seismic sensitive signal at Cotter Arkansas and 11 from the ELF enhanced signal, also at Cotter.

Also, there was another connectivity: an abrupt electric field discontinuity coinciding with the fourth ELF outburst in the sequence of outbursts. T-storm activity was not present in the general area during these recordings [8], and ordinary lightning simply doesn't produce signals like these in the multivariable instrument; that difference includes the vertical strobing in (Figure 10). Note that the discontinuity deflected downward in (Figure 11), which is how the electrometer should behave during a nearby strike by the more common, negative type of lightning, where electrons move downward, toward ground; however, upward moving, underground positive charges of the type proposed by Freund, et al. [9] should also have the same effect.

Finally, the observed ELF frequency, $20.3 \mathrm{~Hz}$, agrees with other observations [10] of possible quake precursors near the second and third harmonics of the Schumann resonance phenomenon. K. Ohta, et al. [10], “...observed anomalous 


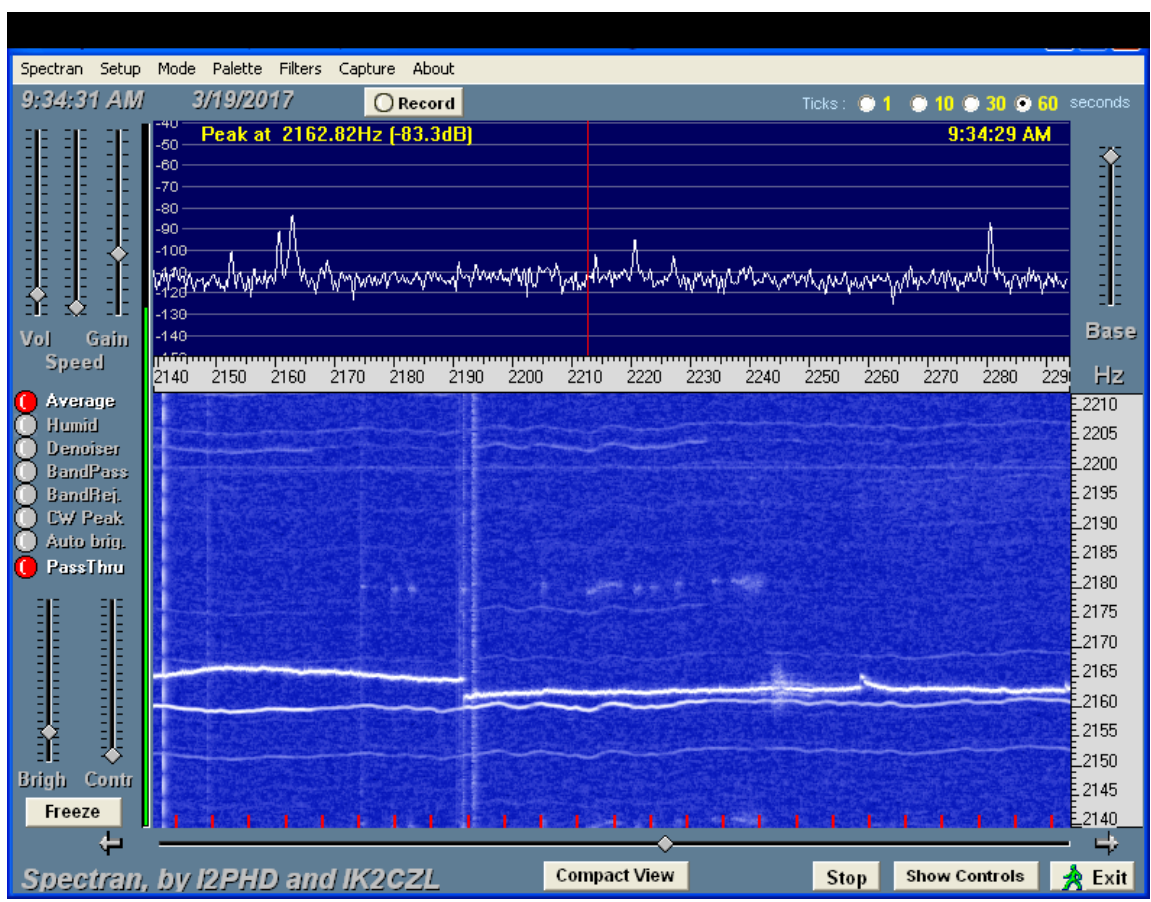

Figure 11. ELF sensitive recording of the 2017-03-19 earthquake that had preceding ELF outbursts. Recorded by the multivariable instrument, COTR2.

excitations of Schumann resonances before large earthquakes, [notably the] Mid-Niigata Prefecture earthquake (2004, M6.8), [and the] Noto-Hantou earthquake (2007, M6.9) in Japan." In the case of the Mid-Niigata Prefecture quake the frequencies with maximum intensities were at $20.60 \mathrm{~Hz}, 20.70 \mathrm{~Hz}$, and 20.80 $\mathrm{Hz}$, thus similar to the Bardwell, $\mathrm{KY}$ event and in both cases fairly close to the atmospheric value of the third Schumann resonance. This quake also followed a period of substantial ELF emissions a little above $16 \mathrm{~Hz}$, about $2 \mathrm{~Hz}$ higher than the ordinary second Schumann harmonic. The Cotter seismometer did not record any comparable second harmonic-associated outbursts during the March 19, 2017 event.

South Hutchinson, Kansas experienced two quakes on 2019-08-16, a mag. 4.2 at 12:59:10 UTC and a mag. 3.1 at 13:10:49 UTC. See (Figure 12), below. The larger quake followed a moderate, $20.3 \mathrm{~Hz}$ ELF outburst by about 23 minutes, and a pair of ELF outbursts also preceded the mag. 3.1 quake by a stagger consistent with the Kansas quake's seismic wave travel time to Cotter. Purely coincidental stagger events are of low probability; see the supplementary material.

It is worth noting that the author was testing an HP Stream 14 laptop that was directly transformer-coupled to house wiring (with no seismometer attached and no unshielded wire, i.e., just recording ELF range signals from the power grid) when a mag. 3.3 quake happened very near the small towns of Gassville and Cotter Arkansas; it was a quake both heard and felt, and it brought many people out of bed, including the author. The laptop was running SPECTRAN II, and something like a Type 3 ELF outburst signal at $\sim 20 \mathrm{~Hz}$ was recorded at the exact time of the quake, 2019-09-12 06:42:22 UTC; see (Figure S2) in the 


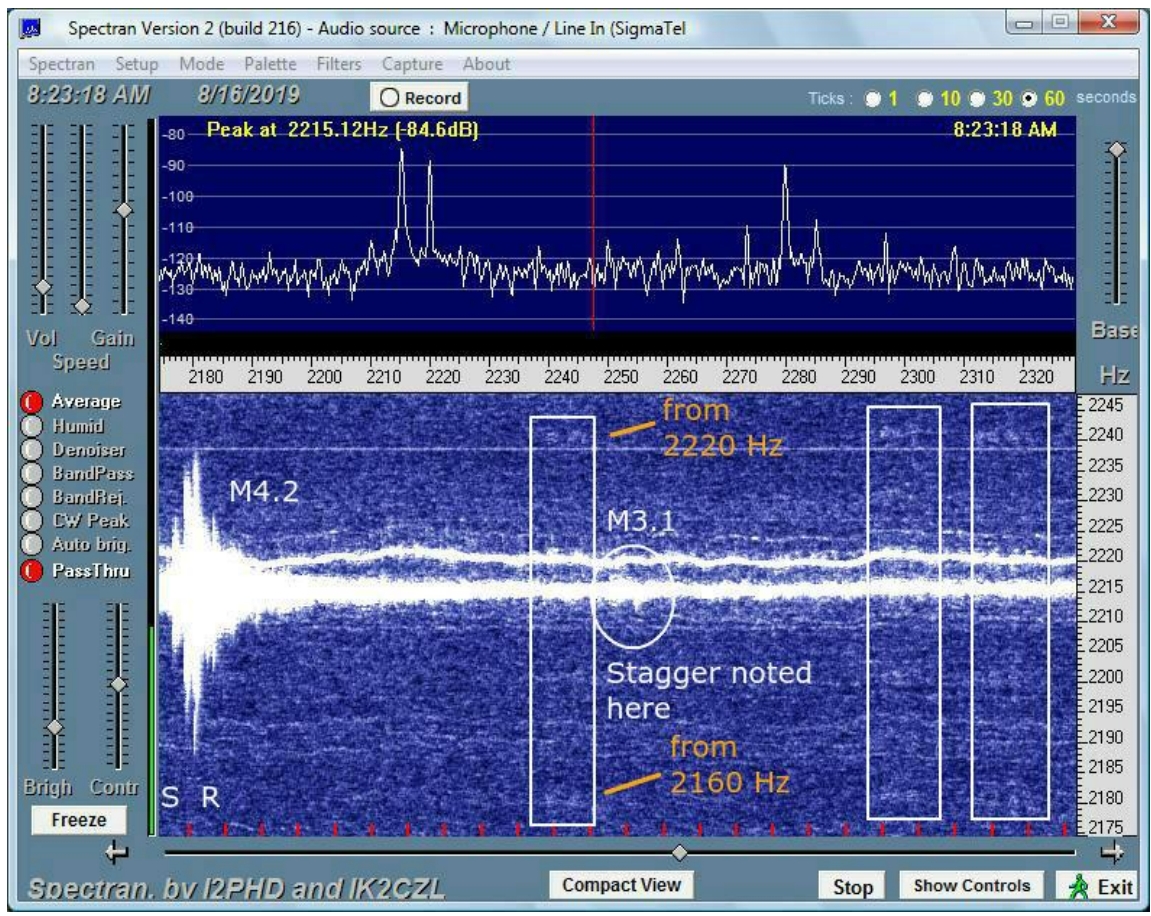

Figure 12. A pair of Kansas earthquakes on 2019-08-16 that had accompanying ELF outbursts. Recorded by the multivariable instrument, COTR2.

supplemental file and a discussion, below, concerning Type 3 ELF outbursts. Seismic wave travel time to Cotter from the quake's focus was perhaps three seconds, and the seismic signal of the COTR2 multivariable instrument immediately went off-scale, effectively overwriting any ELF outburst that might have recorded!

Infrequent ELF outbursts similar to those at $20.3 \mathrm{~Hz}$ in (Figure 10 and Figure 11), though lacking an associated quake, have been recorded at Cotter since 2013 (they were not recognized as natural signals at first). This was soon after the multivariable seismic instrument began operating, and they have continued to the present. The intervals between such quake-free outbursts are random, on the order of a month or so - but sometimes more frequent. In contrast, the recordings of (Figures 10-12) document the only two cases, thus far, where a recorded earthquake was strongly associated with a staggered ELF/seismic wave arrival event.

One more thing needs to be said about the $20.3 \mathrm{~Hz}$ emissions: they generally fall into one of three types:

Type 1-An isolated, brief outburst.

Type 2-A machine-gun fire sequence that essentially draws a dotted line conforming to the shape of the wandering $60 \mathrm{~Hz}$ harmonic that it is heterodyned with.

Type 3-A rounded area, like the final ELF event recorded in (Figure 10 and Figure 11). These signal types are illustrated by recently recorded examples in (Figure 13 and Figure 14), below. 


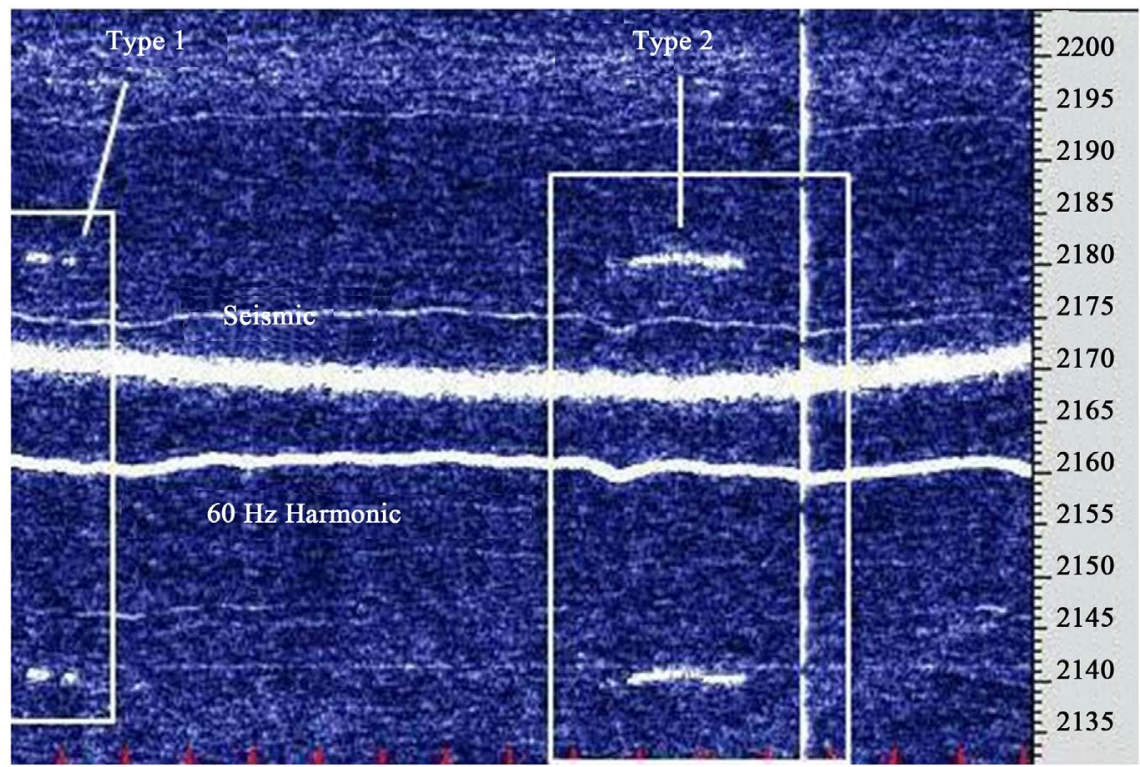

Figure 13. Type 1 and Type 2 ELF signals at $\sim 20 \mathrm{~Hz}$. Recorded by the multivariable instrument, COTR2.

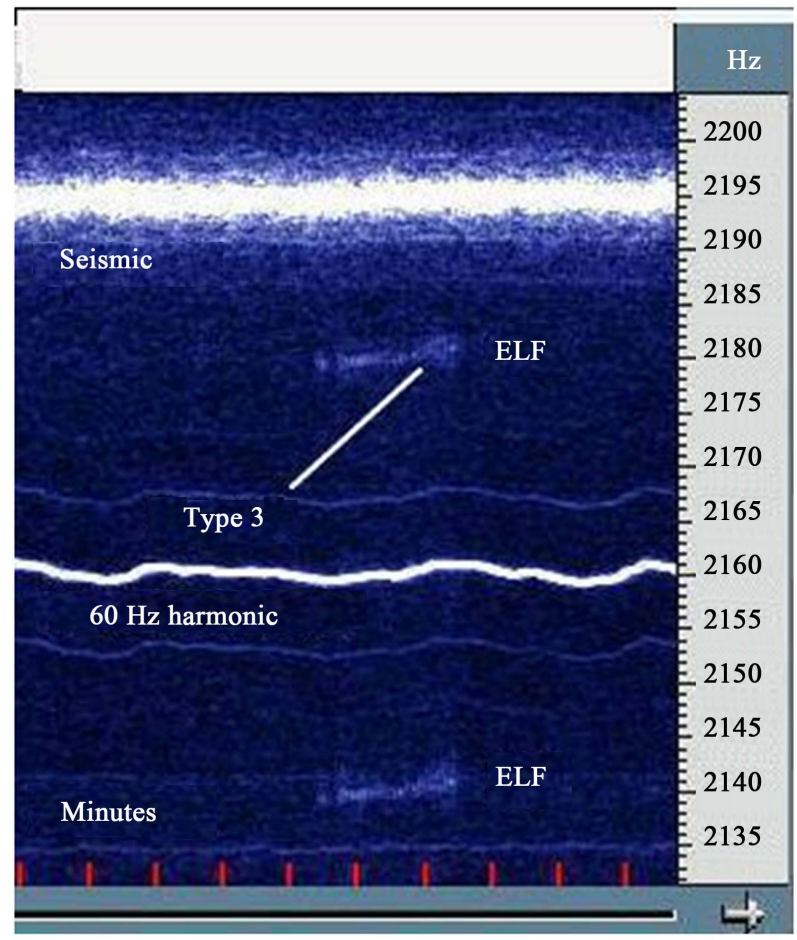

Figure 14. Type $3 \mathrm{ELF}$ signals at $\sim 20 \mathrm{~Hz}$. Recorded by the multivariable instrument, COTR2.

The interactions observed between natural environmental signals and signals native to the power grid are simply heterodyne mixing of the higher harmonics of $60 \mathrm{~Hz}$, such as $2160 \mathrm{~Hz}$, with quake -associated and other kinds of environmental ELF emissions For example, the $20 \mathrm{~Hz}$ signals in (Figure 13 and Figure 14) show up as sum and difference frequencies, respectively, at $\sim 2180$ and $\sim 2140$ 
$\mathrm{Hz}$ relative to $2160 \mathrm{~Hz}$. The $60 \mathrm{~Hz}$ harmonics are viewed here as a carrier frequencies. Others have probably noticed the heterodyned signals, although a literature search didn't find them, and a Rosetta Stone like (Figure 11) is necessary to further assign them as quake-related.

It is possible that the phenomenon observed by K. Ohta, et al. [10] is identical to the rare NMSZ events of (Figure 10 and Figure 11), possibly also to the very similar ELF emissions that are not associated with any detectable earthquakes. The findings reported here speak of a fairly quiescent situation in the NMSZ, at least currently, but do such ELF outbursts transition to the type of thing K. Ohta, et al. recorded as the stress build-up approached a magnitude 6 earthquake? (Figure 15), above, was a recording from the multivariable instrument's first year of operation at Cotter Arkansas, and it documents much stronger and more frequent outbursts of ELF than those recorded in (Figure 10 and Figure 11). The answer seems to be yes, at least someplace, not necessarily the New Madrid zone. The recording of (Figure 15) went on for hours, and emissions were indeed near 15 and $20 \mathrm{~Hz}$, similar to the Schumann second and third harmonics, as described by Ohta, et al. [10] The emission near $30 \mathrm{~Hz}$, A sub-harmonic mid-point relative to power grid $60 \mathrm{~Hz}$ harmonics, e.g., the 36th and 37th, is interesting. Also, there is an obvious $\sim 18$ minute cycle in these data.

A weakness of the multivariable instrument described here is the lack of directionality of its power grid ELF antenna. V. Straser, D. Cataldi and G. Cataldi have been characterizing earthquake-associated premonitory electromagnetic

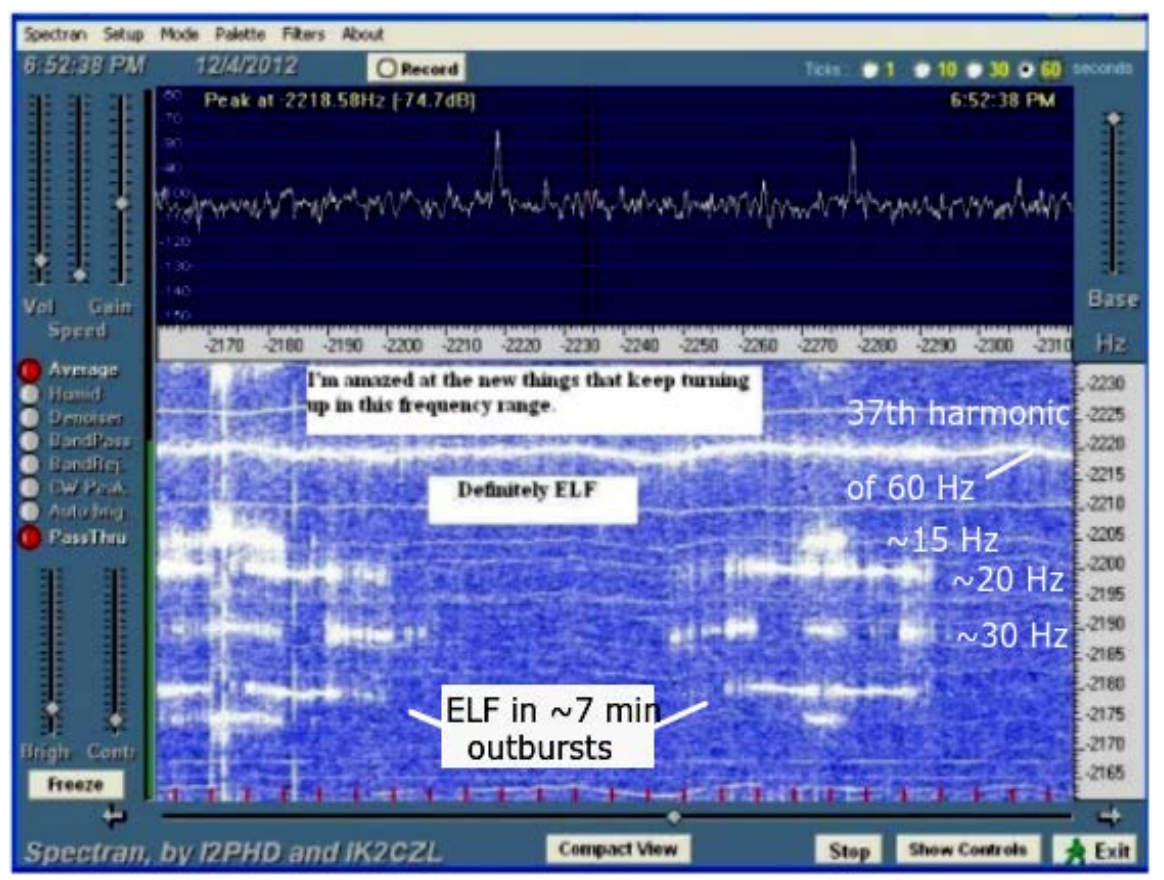

Figure 15. Stronger signals near 15 and $20 \mathrm{~Hz}$ are very similar to those reported by $\mathrm{K}$. Ohta, et al. Recorded by the COTR2/SPECTRAN II system. The seismometer signal was disconnected to reduce clutter. These are heterodyned ELF signals coming from the power grid. 
emissions using a wideband receiving and radio direction finding device, and have reported signals from the azimuth of the New Madrid Seismic Zone from their geophysical observatory's location in Rome Italy, $8500 \mathrm{~km}$ distant [11].

Those signals had frequencies between $1000 \mathrm{~Hz}$ and 32,000 Hz, [11] which includes the narrow range of the multivariable instrument in Cotter, and the author notes that the numerous vertical strobes seen in the right hand half of (Figure 10), following the quake, and also before the quake, see (Figure S1) in the supplemental material, are indicative of wider bandwidth, pre-quake signals outside the multivariable instrument's narrower bandwidth, the upper limit being about $60 \mathrm{~Hz}$ for seismic signals. The seismic carrier frequency is about 2200 $\mathrm{Hz}$. The pre-quake signals observed in the investigation reported here were generally impulses.

\section{Conclusions}

1) The power grid appears to be a practical, inexpensive means for detecting and enhancing both man-made and natural ELF signals, down to about $1 \mathrm{~Hz}$ and possibly lower.

2) The FM seismometer is sensitive and compatible with the multivariable instrument concept.

3) SPECTRAN II processes the seismic, electromagnetic and electric field signals together, in real time, so there is no significant relative time error in the recordings of those three variables.

4) As a result of 3, the ability to discern simultaneous seismic and electromagnetic events at the quake's hypocenter, based on the staggered arrival times of electromagnetic and seismic signals at the seismometer, is a useful property of the multivariable seismometer. Also, electric field effects detected during one of the recorded quakes support including an electrometer in a multivariable seismometer's inventory of sensors.

5) The quake of 2017-03-19, which was preceded by 11 minutes of ELF outbursts near $20 \mathrm{~Hz}$, shows clearly that some oncoming small quakes indeed have premonitory electromagnetic signals, but since there are many more ELF outbursts of the same kind that do not lead to quakes, such signals can't be used for earthquake prediction. It is possible that large quakes are generally preceded by elevated $20 \mathrm{~Hz}$ activity, but that remains to be proven. Finding a reliable oncoming quake predictor is the big, messy problem of quake prediction research.

6) Sensors of the type that create sinusoidal signals are easily added to the existing instrument.

\section{Acknowledgements}

The project had private funding. It is dedicated to my grandchildren, Faron and Asa, who died much too young, and to Betty Hinton, the good student whom I've known since we were both 12 years old, who became my wife. 


\section{Disclaimer}

The device described here is seen only as a tool for earthquake prediction research, not as a device for actually predicting oncoming earthquakes.

\section{Conflicts of Interest}

The authors declare no conflicts of interest regarding the publication of this paper.

\section{References}

[1] Venkatesh, C., Srikanth Kumar, D., Siva Sarma, D.V.S.S. and Sydulu, M. (2008) Modelling of Nonlinear Loads and Estimation of Harmonics in Industrial Distribution System. Fifteenth National Power Systems Conference (NPSC), IIT Bombay, December 2008, 592-597.

[2] Footnote-Information Concerning the Numerical Electromagnetics Code Can Be. https://en.wikipedia.org/wiki/Numerical_Electromagnetics_Code

[3] Armstrong, E.H. (1936) A Method of Reducing Disturbances in Radio Signaling by a System of Frequency Modulation. Proceedings of the IEEE, 24, 689. https://doi.org/10.1109/JRPROC.1936.227383

[4] Footnote-Theory and Technology of FM Modulation. https://en.wikipedia.org/wiki/Frequency_modulation

[5] Footnote-The WINDOWS Version of SPECTRAN II Is Found Here. https://www.sdradio.eu/weaksignals/spectran.html

[6] Cohen, M.B. and Gołkowski, M. (2013) HAARP Includes Electrojet Scanning for ELF Synthesis at Frequencies Down to $0.1 \mathrm{~Hz}$, and Often Transmitted as Square Wave Signals. Journal of Geophysical Research: Space Physics, 118, 6597. https://en.wikipedia.org/wiki/High_Frequency_Active_Auroral_Research_Program https://doi.org/10.1002/jgra.50558

[7] Tavakoli, B., Pezeshk, S. and Cox, R.T. (2010) Seismicity of the New Madrid Seismic Zone Derived from a Deep-Seated Strike-Slip Fault. Bulletin of the Seismological Society of America, 100, 1646-1658. https://doi.org/10.1785/0120090220

[8] Footnote-There Were No Thunderstorms Near the NMSZ during the 2017-03-19 Seismic Event. The Area Was Well behind a Cold Front. https://www.wpc.ncep.noaa.gov/dailywxmap/index_20170319.html

[9] Freund, F. (2002) Charge Generation and Propagation in Igneous Rocks. Journal of Geodynamics, 33, 543-570.

https://www.quakefinder.com/research/EQTdata/Freund\%20paper\%20Sept_2004.p df https://doi.org/10.1016/S0264-3707(02)00015-7

[10] Ohta, K., Izutsu, J., Furkawa, K. and Hayakawa, M. (2008) Anomalous Excitation of Schumann Resonances Associated with Huge Earthquakes, Chi-Chi (China, 1999), Niigata-Chuetsu (Japan, 2004), Noto-Hantou (Japan, 2007), Observed at Nakatsugawa in Japan. Proceedings of the 7 th International Conference "Problems of Geocosmos", St. Petersburg, Russia, 26-30 May 2008.

[11] Straser, V., Cataldi, D. and Cataldi, G. (2019) Electromagnetic Monitoring of the New Madrid Fault US Area with The RDF System-Radio Direction Finding of the Radio Emissions Project. New Concepts in Global Tectonics Journal, 7, 43. 


\section{Supplementary Material}

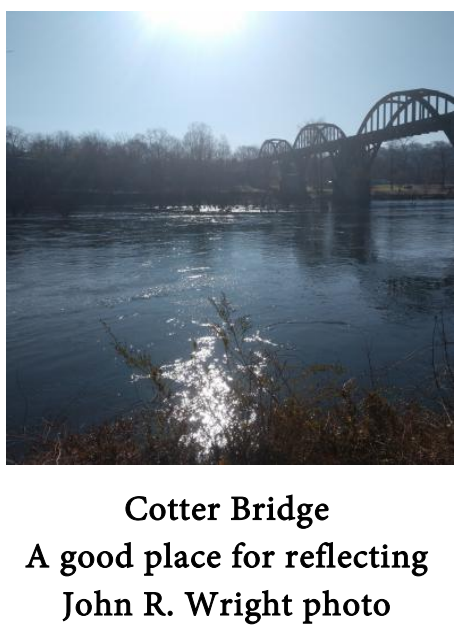

The following material might or might not be perceived by reviewers and readers as supplementary items. (Figure S1), below, is the recording frame immediately preceding (Figure 10). The figure actually is a redundant supplemental because it also has the first three $20 \mathrm{~Hz}$ ELF outbursts, followed by a fourth ELF outburst that occurs simultaneously with a strobe and the vertical discontinuity near the right hand end of the (Figure S1) recording, seen so easily in (Figure 11) You can barely see those four ELF outbursts in (Figure S1). The smooth-textured, vertical strobes observed in the latter figure are probably quake related, too, and they speak of electrical activity.

Similarly, (Figure 13 and Figure 14) are redundant with the same three signal types seen in 10 and 11; but all of those must be kept in the manuscript. The author wanted the reviewers and readers to appreciate the fact that the ELF outburst "shape" phenomenon has this property, generally. (Figure 15) also shows it, and that figure definitely belongs in the paper.

(Figure S2), see below, records ELF range signals, and has no seismic signal. It is electrically very noisy; the interface is wired directly to the power grid.

The Type 3-like outburst, circled with red ink, is close to $20 \mathrm{~Hz}$ and coincided with a very nearby seismic event, but there wasn't any believable evidence of symmetry around the $2220 \mathrm{~Hz}$ harmonic of $60 \mathrm{~Hz}$. The author is suspicious. There is a symmetry rule involved here; sum and difference frequencies are expected.

Further commenting on (Figure S2): The harmonic is $60 \mathrm{~Hz} \times 37=2220 \mathrm{~Hz}$, a source already demonstrated to mix with man-made and natural ELF signals, but apparently not those half-moon shaped signal overloads-some of those are asymmetric with respect to $2220 \mathrm{~Hz}$. The red-circled area is more like natural ELF outbursts. Its time interval, almost a minute, includes that of the 3.3 mag. Gassville/Cotter quake of 2019-09-12 (06 42 22 UTC), and the frequency is also very close to $-20 \mathrm{~Hz}$, i.e., $2200 \mathrm{~Hz}$. But the expected second, upper $(+20 \mathrm{~Hz})$ heterodyne product isn't at $2240 \mathrm{~Hz}$. The author thus seriously doubts a valid signal 


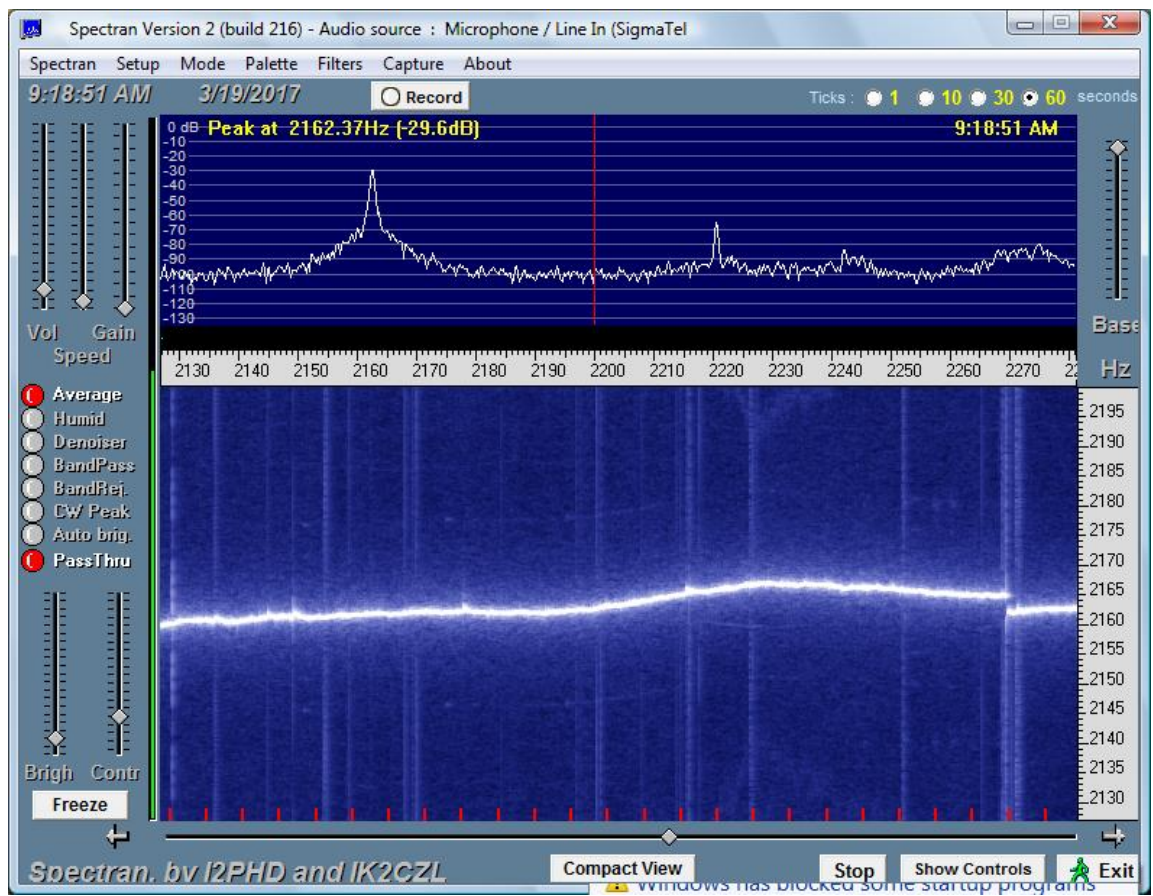

Figure S1. COTR2 recording of the 2D data frame immediately before (Figure 10).

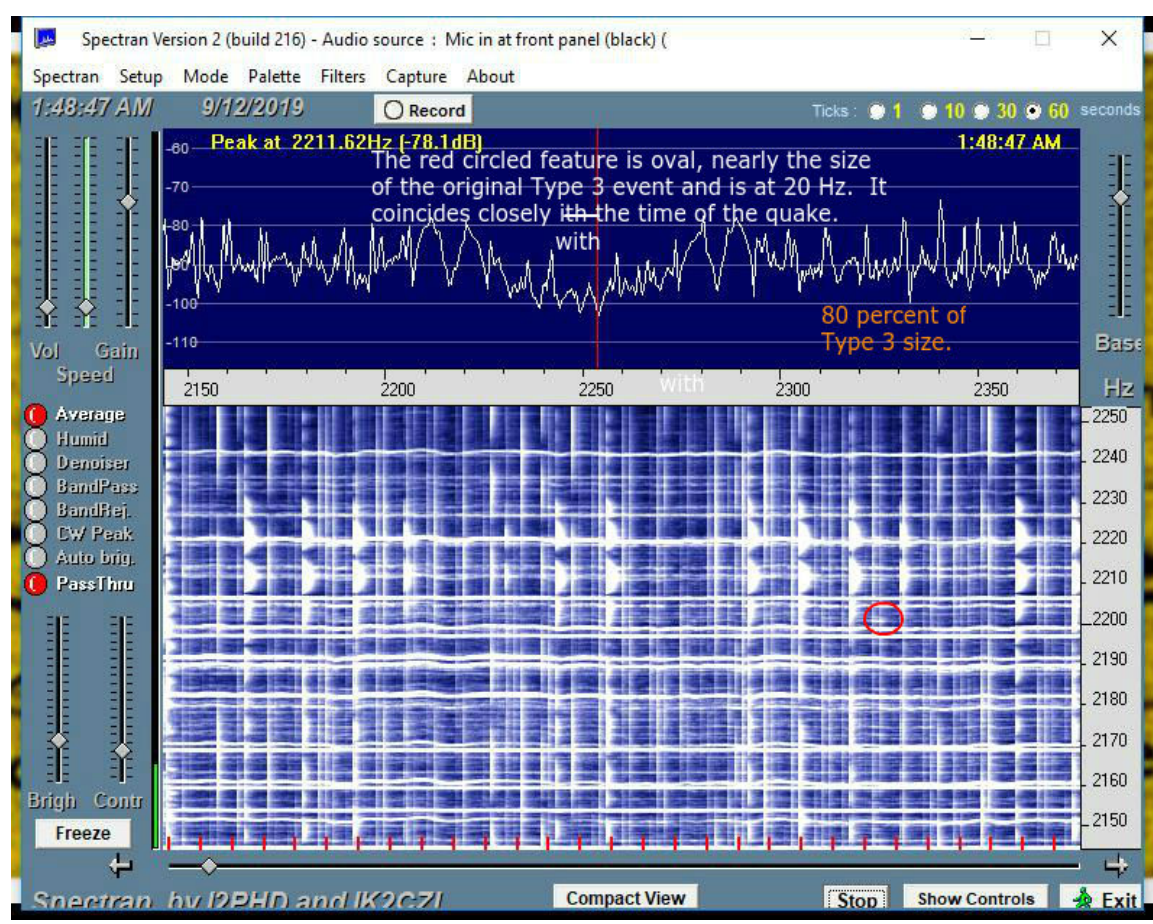

Figure S2. An unexpected outcome of a hard-wired power grid interface experiment.

at $-20 \mathrm{~Hz}$. There is a remote possibility that a phasing effect in the experimental interface cancelled the $+20 \mathrm{~Hz}$ signal.

The probability of staggered arrival quakes

In (Figure 10) and (Figure 11), the probabilities of random ELF-seismic stagger depend on how probabilities are defined. Total ELF activity is maybe 3 
min., not $11 \mathrm{~min}$, and if the interval between such events is a month $(43,200$ $\mathrm{min})$, the probability of a random coincidence with an ELF outburst is about $(\sim 3$ $\mathrm{min} / 43,200 \mathrm{~min})=0.000069$. Alternatively, if only the type 3 event could be implicated, the probability would be a little lower $(\sim 1 \mathrm{~min} / 43,200)=0.000023$, etc., and this completely ignores the seismic contribution to ELF-seismic stagger event probabilities. Pursuing the latter, the study reported here found only two interesting stagger events in a $\sim 29$ month interval-about $1.25 \times 10^{6}$ minutes, where the ELF/seismic wave arrival time difference has to agree within $0.1 \mathrm{mi}-$ nutes! We are not dealing with high probabilities if the observed stagger events with the correct arrival times are purely coincidental, i.e., $0.1 / 1.25 \times 10^{6}$, or 0.00000008 . The ELF and seismic probabilities then multiply, and the result is a very low $\sim 2 \times 10^{-12}$. This is a very crude estimate, and I couldn't bring myself to include it in the paper simply because my education is in chemistry, not seismology. I'd rather give this task to an experienced seismologist, who would have much better insight for it than I do. 